\title{
Interspecific Comparison of a Drosophila Gene Encoding FMRFamide-Related Neuropeptides
}

\author{
Paul H. Taghert and Lynne E. Schneider \\ Department of Anatomy and Neurobiology, Washington University School of Medicine, Saint Louis, Missouri 63110
}

In order to identify functionally important regions of a neuropeptide gene in Drosophila melanogaster, we have studied its occurrence in related species and have characterized the structure of a homologous gene in Drosophila virilis. The melanogaster gene encodes a precursor that contains 13 neuropeptides related to the molluscan tetrapeptide FMRFamide (Nambu et al., 1988; Schneider and Taghert, 1988). Using the melanogaster gene as a probe in Southern blot analysis, related sequences were detected in DNA from each of 7 species tested. $D$. virilis, which is estimated to have diverged from $D$. melanogaster between 60 and 80 million years ago (Throckmorton, 1975), was chosen for more detailed study. Immunocytochemical staining using an antibody to authentic FMRFamide revealed a similar set of immunoreactive neurons in the CNS of larvae from the 2 Drosophila species.

Using a melanogaster gene probe, overlapping clones were isolated from a virilis genomic library; DNA sequence analysis indicated the presence of a homologous gene. Comparisons of the genes and deduced proteins between the 2 species revealed the following points. (1) Both genes are divided into 2 exons: in $D$. melanogaster the exons are 106 and 1352 bp long; in $D$. virilis, they are 169 and at least 1232 bp long; in both species, the intron is approximately $2.5 \mathrm{~kb}$ long. (2) The sequence of exon I has largely diverged, and in neither species are exon I sequences translated. In this vicinity of the gene, sequence conservation is limited to a 67 bp region that spans the TATA box and the RNA start site. (3) The deduced neuropeptide precursors have very similar sizes ( 347 vs 339 amino acids) and the presumed signal sequences are perfectly conserved. (4) While the me/anogaster precursor contains 13 FMRFamide-related peptides, the virilis precursor contains only 10 . (5) The sequences of some but not all of the FMRFamide-like peptides are perfectly conserved. (6) In the rest of the precursor, significant sequence conservation is found only in the $\mathrm{N}$-terminal portion; immediately downstream of the final FMRFamide-like peptide, the protein sequences are highly

\footnotetext{
Received Nov. 21. 1989; revised Dec. 28, 1989; accepted Jan. 4, 1990.

We thank Bill Gelbart for providing the $D$. virilis genomic library and Jay Hirsch for communicating unpublished results. Kyoko Marayuma kindly provided animals of representative Drosophila species; we also thank Kyoko Marayuma and Larry Salkoff for their comments on a draft of the manuscript. This work was supported by grants from the NIH (NS-21749) and from the Washington University-Markey Center for the Molecular Biology of Human Genetics to P.H.T.

Correspondence should be addressed to Paul H. Taghert, Department of Anatomy and Neurobiology, Washington University School of Medicine, 660 South Euclid Avenue, St. Louis, MO 63110.

Copyright $C$ : 1990 Society for Neuroscience $0270-6474 / 90 / 061929-14 \$ 02.00 / 0$
}

divergent. (7) 5' to the RNA start sites (1.2 kb of melanogaster DNA and $1.8 \mathrm{~kb}$ of virilis DNA), $17 \mathrm{small}$ (9-52 base pairs) regions are evolutionarily conserved (>80\% sequence conservation). We discuss neuropeptide biosynthesis, the functions and evolution of FMRFamide-like neuropeptides in insects, and the cell-specific regulation of neuropeptide gene expression in the contexts of these results.

FMR Famide was first purified as a cardioregulatory neuropeptide from the CNS of the clam (Price and Greenberg, 1977). In addition to its modulation of cardiac output (Price and Greenberg, 1977; Painter, 1982), the peptide has well-defined roles in modulating the actions of neurons (Cottrell et al., 1984; Boyd and Walker, 1985; Columbaioni et al., 1985) and in regulation of evoked muscle tension (Doble and Greenberg, 1982; Weiss et al., 1984; Muneoka and Matsuura, 1985). Using an antiFMRFamide antiserum as the primary tool of purification, numerous biologically active peptides from a host of diverse animal genera have been purified. In the case of Aplysia, the endogenous peptide is the same as authentic FMRFamide (Schaefer et al., 1985). In many other cases, however, the related peptides are longer by virtue of extensions at the $\mathrm{N}$-termini. In various molluscan species, FMRFamide is one of a group of structurally related peptides that include FLRFamide, SPFLRFamide, and several heptapeptides with the general sequence XDPFLRFamide [X is pGlu, Gly, Ser, or Asn (Ebberink et al., 1987; Price et al., 1985, 1987a, b)]. Similarly, SDRNFLRFamide and TNRNFLRFamide were purified from lobster CNS (Trimmer et al., 1987), and 2 immunoreactive bovine peptides with anti-analgesic properties were purified by Yang et al. (1985). In Drosophila, the predominant FMRFamide-like immunoreactive peptide is DPKQDFMRFamide (Nambu et al., 1988); cloning and sequencing of the Drosophila FMRFamide gene has indicated that this and related peptides are cosynthesized as parts of a large precursor (Nambu et al., 1988; Schneider and Taghert, 1988). Both the Drosophila and Aplysia (Taussig and Scheller, 1986) FMRramide genes share sequence homologies with mammalian genes encoding the opioid peptides and corticotrophin-rclcasing factor.

Extensive physiological characterizations of FMRFamide-related peptides in molluscs have been reported, but the roles of similar peptides in insects are not well defined. Their effects have been studied at the neuromuscular junction of locust (Evans and Myers, 1986; Walther and Schiebe, 1987), where they modulate tension produced by the stimulation of an identified motorneuron. YGGFMRFamide was found to be an order of magnitude more potent than was FMRFamide in this prepa- 
ration. Although the endogenous FMRFamide-like peptides in the locust have not been defined, these results support the hypothesis that they are likely to include $\mathrm{N}$-terminally extended forms, as are found in Drosophila. FMRFamide-like immunoreactivity is present in neurohemal organs of the moth CNS and can be released upon depolarization (Carroll et al., 1986). The principle neurons expressing the FMRFamide gene in the Drosophila CNS are a set of segmentally homologous neuroendocrine neurons (Schneider, et al., 1988, and in preparation). Together these results suggest that, in insects, a salient role for FMRFamide-like peptides may be as hormonal modulators of peripheral synapses and target organs. Because the gene is also expressed by interneurons (L. E. Schneider, M. A. O'Brien, and P. H. Taghert, unpublished observations), it is possible that the peptides may play similar modulatory roles at central synapses.

The Drosophila FMRFamide precursor is comparable to other neuropeptide precursors (e.g., Noda et al., 1982; Mahon et al., 1985; Schaefer et al., 1985) in that it contains diverse yet related neuropeptides: some are multiply represented, while others are uniquely present. These features of neuropeptide precursor organization raise a number of interesting questions relating to neuropeptide biosynthesis and function. For example, is the copy number of a specific neuropeptide within a precursor critical for its functions? To what extent do slightly divergent peptide sequences mediate different peptide functions? Such questions are difficult to answer using standard physiological experiments, due to both the potential diversity of neuropeptide sequences and to a lack of specific pharmacological antagonists. In this regard, a complementary molecular and genetic approach in Drosophila would be of value.

We have isolated and characterized a gene from $D$. virilis that is homologous to the FMRFamide neuropeptide gene of $D$. melanogaster. The goal in comparing the DNA sequences of the 2 species is to identify evolutionarily conserved features of both the protein-coding regions and potential regulatory regions. Previous studies (Blackman and Meselson, 1986; Treier et al., 1989; Johnson et al., 1989) have shown that $D$. virilis is sufficiently diverged from $D$. melanogaster to predict that sequence conservation should be restricted to functionally important regions. Based on this assumption, the comparison is informative regarding the significance of neuropeptide gene exons and of the size of the neuropeptide precursor. In addition, the 2 species demonstrate a remarkable degree of variability in peptide sequences and copy number. Finally, conserved regions in the putative promoter region are useful in defining DNA regions that may regulate the expression of the gene.

\section{Materials and Methods}

DNA extraction. A total of 50 animals from a given species was homogenized in a glass mortar and pestle in $500 \mu \mathrm{l}$ of $0.1 \mathrm{M} \mathrm{Tris}-\mathrm{HCl}(\mathrm{pH}$ 9.0), $0.1 \mathrm{~m}$ EDTA, $1 \%$ SDS, and $1 \%$ DEPC. Then, $70 \mu 1$ of $8 \mathrm{M} \mathrm{KOAC}$ was added and the homogenate chilled and centrifuged; $1 / 2$ volume of isopropanol was added to the supernatant and the DNA collected by centrifugation.

Genomic Southern blots. Genomic Southern blots were performed as described by Maniatis et al. (1982). After blotting to Nytran membranes (Schleicher and Schuell, according to the manufacturer's recommendations), prehybridization and hybridizations were performed at $42^{\circ} \mathrm{C}$ in a solution containing $30 \%(\mathrm{vol} / \mathrm{vol})$ formamide, $6 \times \mathrm{SSC}(1 \times \mathrm{SSC}$ $=0.15 \mathrm{M} \mathrm{NaCl} / 0.015 \mathrm{M}$ sodium citrate, $\mathrm{pH}, 7.0) 0.1 \%$ Sarkosyl, salmon sperm DNA at $100 \mu \mathrm{g} / \mathrm{ml}$, and $1 \%$ dry milk. The probe was a $962 \mathrm{bp}$ R 1-Pst I fragment of the Drosophila FMRFamide cDNA B(8) (Schneider and Taghert, 1988) that was labeled by random hexamer priming (specific activity, $\left.\sim 5 \times 10^{8} \mathrm{cpm} / \mu \mathrm{g}\right)$. Filters were washed at $47^{\circ} \mathrm{C}$ in $2 \times$
$\mathrm{SSC} / 0.1 \%$ Sarkosyl or at $65^{\circ} \mathrm{C}$ in $0.1 \times \mathrm{SSC} / 0.1 \%$ Sarkosyl, then dried, and autoradiographed.

Isolation and characterization of $\mathrm{D}$. virilis FMRFamide clones. Approximately 240,000 clones from a lambda EMBL $4 D$. virilis genomic library were screened by the technique of Benton and Davis (1977) using the same conditions as in the genome blot experiments (washed at $47^{\circ} \mathrm{C}$ ) but with a $1 \mathrm{~kb}$ "upstream" Pst I fragment of melanogaster genomic DNA that immediately precedes the FMRFamide gene start site (Schneider and Taghert, 1990). Positive clones were rescreened with the $962 \mathrm{bp}$ cDNA probe used for the genome blot experiments. Clones that were positive for both hybridization probes were further characterized by restriction endonuclease mapping and blotting procedures. Hind III and Xba I fragments that hybridized to either the cDNA or "upstream" probes were subcloned into the Bluescribe plasmid.

DNA sequencing methods and analysis. Plasmid DNA was alkali denatured and sequenced by using a commercially available kit (Sequenase, U.S. Biochemicals), $\alpha-\left[{ }^{35}\right.$ S-dATP $]$ and buffer gradient acrylamide gels. Amino acid and nucleic acid identities were computed in the manner of Nambu and Scheller (1986) and are described in the legend to Figure 7.

Immunocytochemistry. A rabbit anti-FMRFamide antiserum was produced by conjugating the peptide (Sigma, Saint Louis, MO) to thyroglobulin with carbodiimide. Peptide conjugates containing $100 \mu \mathrm{g}$ peptide were emulsified in Freund's complete adjuvant and injected subdermally at multiple sites. Conjugate solutions emulsified in incomplete adjuvant were used for boost injections every other week for 6 weeks, and once a month thereafter. Blood was collected 5-7 d following each monthly boost. In radioimmunoassays, the serum contained a low titer of specific antibody (M. A. O'Brien, C. R. Conway, and P. H. Taghert, unpublished observations). However, in immunocytochemical experiments, useful staining was observed with a 1:5000 dilution of the serum. All neuronal staining with the anti-FMRFamide antiserum was blocked by preincubating the diluted antiserum solution with $100 \mu \mathrm{g} /$ $\mathrm{ml}$ authentic FMRFamide overnight at $4^{\circ} \mathrm{C}$ prior to tissue incubation.

Whole-mount antibody staining was performed on third instar animals of both species in the following manner. The body was opened by a mid-dorsal incision and pinned open; Bouin's fixative was applied (after removing extraneous tissues) with the nervous system still connected to the body and to the imaginal disks. Following fixation at $4^{\circ} \mathrm{C}$ for $24 \mathrm{hr}$, the tissues were dehydrated in an ethanol series (including the use of a saturated $\mathrm{LiCO}_{2} / 70 \% \mathrm{EtOH}$ solution to remove picric acid), rehydrated, then stained with the antiserum to authentic FMRFamide. The primary antiserum was used at a concentration of 1:5000, along with Triton X-100 (at $0.3 \%$ ) normal goat serum (at $3 \%$ ), $\mathrm{NaN}_{3}$ (at $0.01 \%$ ), in PBS; primary antiserum incubation lasted for $48 \mathrm{hr}$ at $4^{\circ} \mathrm{C}$ following which the tissues were repeatedly rinsed in PBS with $0.1 \%$ Triton X-100 overnight at $4^{\circ} \mathrm{C}$. The tissues were then processed for HRP-based immunocytochemical detection using a commercially available kit (Vector Labs., Burlingame, CA) or for fluorescence visualization using FITC-conjugated anti-rabbit antibodies (Sigma). The gut and CNS were dissected free of the body and imaginal disks, and mounted in $90 \%$ glycerol/PBS (containing phenylenediamine at $1 \mathrm{mg} / \mathrm{ml}$ ) for viewing with fluorescence or with Nomarski optics, and for photography and drawing at up to $650 \times$.

\section{Results}

Presence of FMRFamide-related sequences in various Drosophila species

Genomic Southern blotting experiments revealed that each of the 7 Drosophila species tested contained restriction fragments that hybridized to a $D$. melanogaster FMRFamide gene probe (Fig. 1). Varying degrees of hybridization were observed among the different species. D. simulans, D. mauritiana, and D. yakuba (closely related species of the melanogaster subgroup) all gave strong signals that persisted in stringent washing conditions. In Figure 1, the yakuba signals appear weak due to less DNA in the digests. $D$. pseudoobscura is more distantly related to melanogaster than are mauritiana, simulans, and yakuba, but it is still a member of the same subgenus (Sophophora). D. funebris, D. virilis, and Zaproinus inermis are the most distantly related of the set. $D$. funebris and $D$. virilis are members of a different subgenus (Drosophila) and $Z$. inermis is a member of the genus 


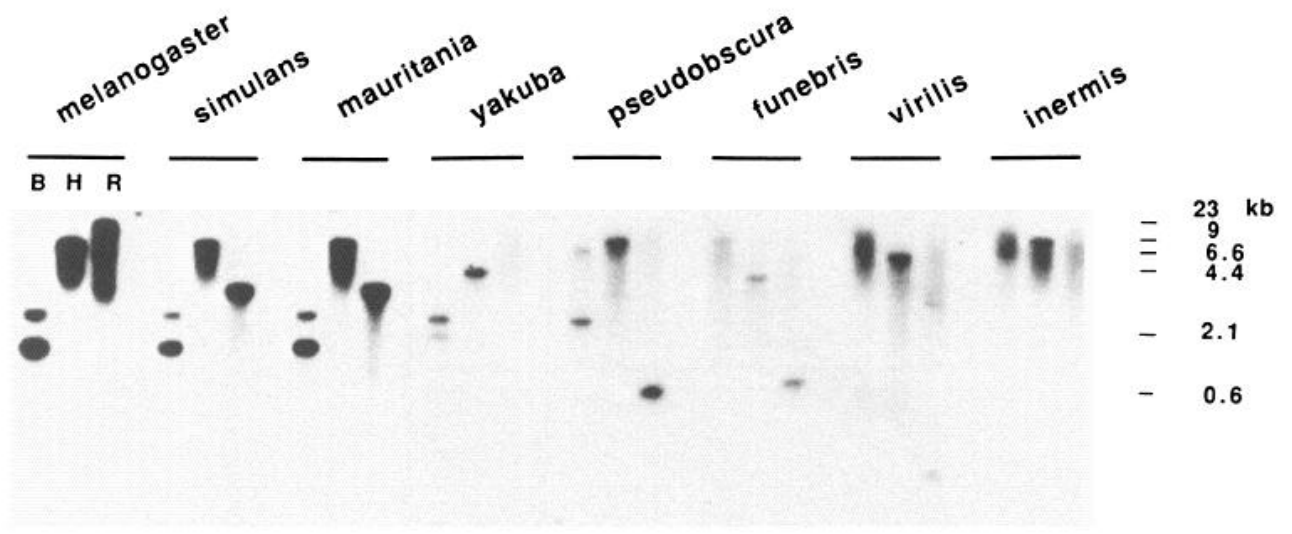

Figure 1. Southern blot analysis of genomic DNA from 8 Drosophalid species: using a melanogaster FMRFamide gene probe, specific hybridization signals are seen in the case of each species included. Each lane represents $\sim 10 \mu \mathrm{g}$ DNA from a given species that was digested to completion with either of 3 restriction enzymes: Bam HI (B), Hind III (H), or Eco RI (R). The 3 lanes marked D. yakuba received only $\sim 3 \mu \mathrm{g}$ DNA. A hexamerlabeled 962 bp R 1-Pst I restriction fragment (representing most of the open reading frame of the melanogaster FMRFamide gene) was used as a probe at lowered stringency (see Materials and Methods for conditions used). DNA size markers are given at right (in kb).
Zaprionus, which is related to the genus Drosophila. Signals from DNA of these species were considerably weaker and, upon high-stringency washing, were lost.

\section{FMRFamide-like immunoreactivity in D. melanogaster and D. virilis}

White et al. (1986) first used anti-FMRFamide antibodies for specifically staining a stereotyped set of $\sim 35$ neurons in the CNS of Drosophila melanogaster. Using a newly prepared antiFMRFamide antiserum on the melanogaster CNS, we have found a similar, although more extensive, set of $\sim 50$ neurons. Much of this immunoreactivity is likely due to expression of the DPKQDFMRFamide gene (Schneider and Taghert, 1988), as indicated by comparison with results from in situ hybridization histochemistry (Schneider et al., 1988; Schneider et al., unpublished observations). The CNS and gut from both $D$. melanogaster and D. virilis were stained using the anti-FMRFamide antiserum (Fig. 2), and the patterns of immunoreactive neurons were compared (Fig. 3). Few differences were found: the most prominently staining cells of the brain (MP, LP, and SP cells) and ventral nerve cord (SE and Tv cells) were equally so in $D$. virilis. Likewise, scattered groups of small neurons (these demonstrated light to moderate staining, e.g., the Td cells) were found in both species. For the case of a few identifiable cell groups, the number of cells per group was often reliably different between species. For example, the virilis Tv cell group typically consisted of 1 large neuron accompanied by 2-3 small immunoreactive cells; in melanogaster, the 1 large Tv cell was often unaccompanied, and only infrequently accompanied by a single small cell. All staining was blocked by preabsorbing the diluted antiserum in $100 \mu \mathrm{g} / \mathrm{ml}$ authentic FMRFamide (data not shown).

\section{Isolation and sequencing of FMRFamide-homologous clones}

A genomic clone ( $\lambda$ Mt -8$)$ that contains sequences encoding the FMRFamide gene was previously isolated from a $D$. melanogaster phage library (Schneider and Taghert, 1988); the organization of the gene was determined by DNA sequencing, primer extension, and nuclease protection assays (Schneider and Taghert, 1990). A $\sim 1 \mathrm{~kb}$ Pst I restriction fragment (from the region lying immediately 5 ' upstream of the RNA start site) was used as a hybridization probe to screen a $D$. virilis genomic library at lowered stringency. Five positive clones were purified and rescreened with a 962 bp RI-Pst I fragment (this second probe represented most of the protein-encoding region of the melanogaster gene); all 5 clones contained hybridizing regions to this second probe as well. We concluded that the virilis clones contained the entire gene including a substantial portion of $5^{\prime}$ upstream regions. Phage clone V6 was chosen for further study; a partial restriction map is shown in Figure 4, along with the positions of 2 regions ( $\mathrm{v}-\mathrm{A}$ and $\mathrm{v}-\mathrm{B}$ ) chosen for subcloning and sequence analysis.

\section{Characterization of the $\mathrm{D}$. virilis gene and deduced FMRFamide precursor}

A long open reading frame of 1029 bp was found in virilis genomic clone V6 that encodes a deduced protein that is highly similar to the DPKQDFMRFamide precursor of melanogaster (Fig. 5). In the case of melanogaster, the initiator ATG codon has been assigned to the first nucleotide of exon II (Schneider and Taghert, 1990). In the case of virilis, the initiator codon is found at position +12 of exon II: this assignment relied on the positions of conserved sequences preceding and defining the $3^{\prime}$ end of the intron. We defined the acceptor splice junction of the virilis intron based on the following sequence features. First, 2 sequences that matched previously described 3 ' intron splice signals (Keller and Noon, 1984) were found at positions -85 and at -51 ; both of these regions were highly conserved between the 2 Drosophila species (Fig. 5). Further, the second such "signal" was followed in each species by a CT-rich region lacking in AG dinucleotides. These are typical features preceding intron splice sites (Padgett et al., 1986). In the case of virilis, the first and only AG di-nucleotide of this region was found 12 base pairs upstream of the initiator ATG.

The deduced open reading frames generated proteins with very similar sizes: melanogaster, 347 amino acids; virilis, 339 amino acids. Each begins with a hydrophobic signal peptide region that is precisely conserved for a length of 23 amino acids (AA). FMRFamide-like peptides are found in each precursor, their organization is the same in each, and all are N-terminally extended. However, the virilis precursor contains 3 fewer peptides than does that of melanogaster (Fig. 6). The melanogaster precursor contains 13 FMRFamide-containing peptides, the first (m1) is followed by a 27 AA spacer region, then a group of 8 FMRFamide-like peptides (m2a-m4), a second short spacer region of $6 \mathrm{AA}$, and then a final group of four FMRFamidelike peptides (m5-m8); the virilis precursor contains a total of 

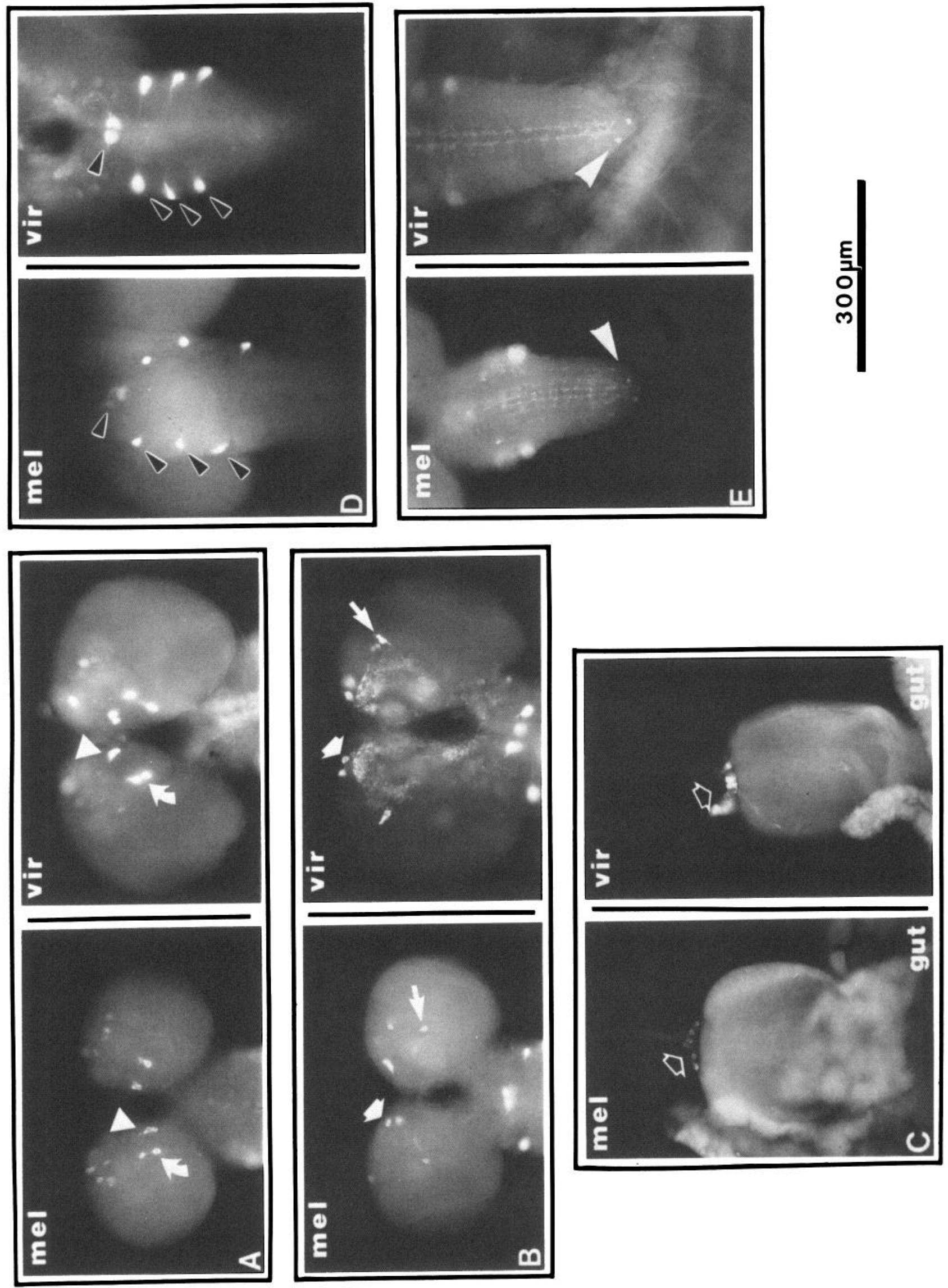


\section{Drosophila melanogaster}

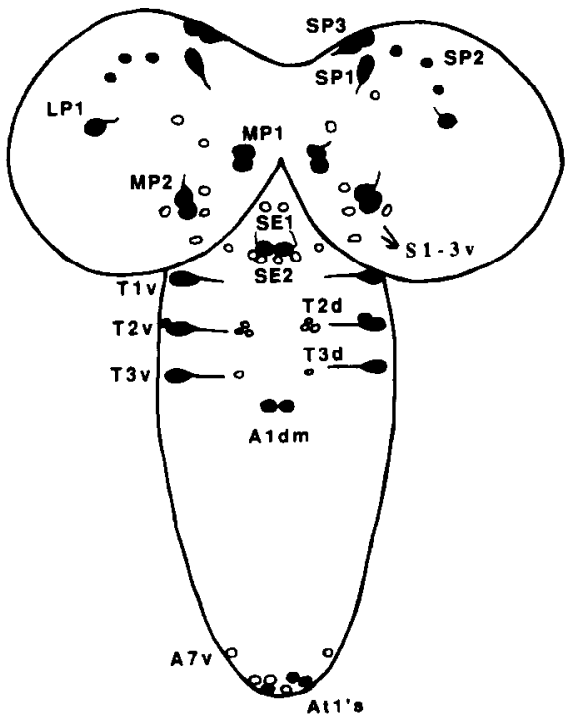

\section{Drosophila virilis}

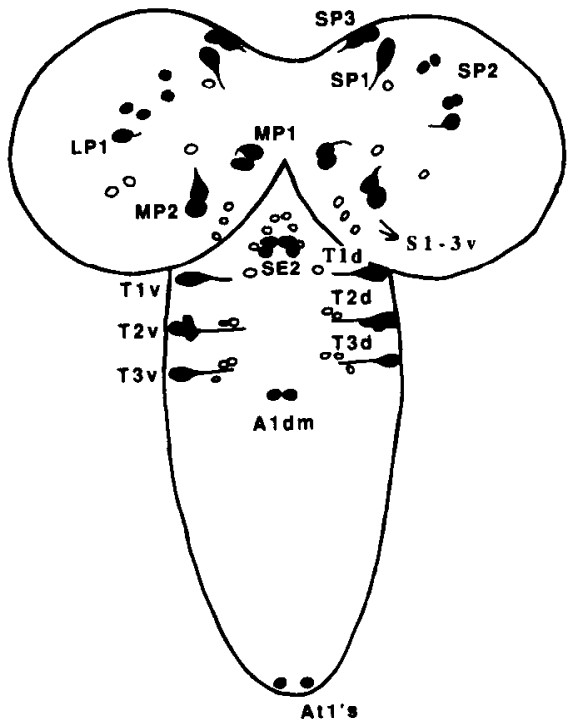

Figure 3. Schematic diagrams that indicate the similar number and positions of FMRFamide-immunoreactive cell bodies in the central nervous systems of $D$. melanogaster and $D$. virilis. Filled symbols represent strongly staining neurons and open symbols represent lightly staining neurons. Abbreviations: $M P$, medial protocerebrum; $L P$, lateral protocerebrum; $S P$, superior protocerebrum; $S E$, subesophageal; $S I-$ 3 and $T 1-3$. subesophageal and thoracic segments $1-3$ respectively; $A l-7$, abdominal segments $1-7$ respectively. Lowercase $d$ and $v$ indicate dorsal versus ventral cell body positions; lowercase $m$ indicates a medial cell body position.
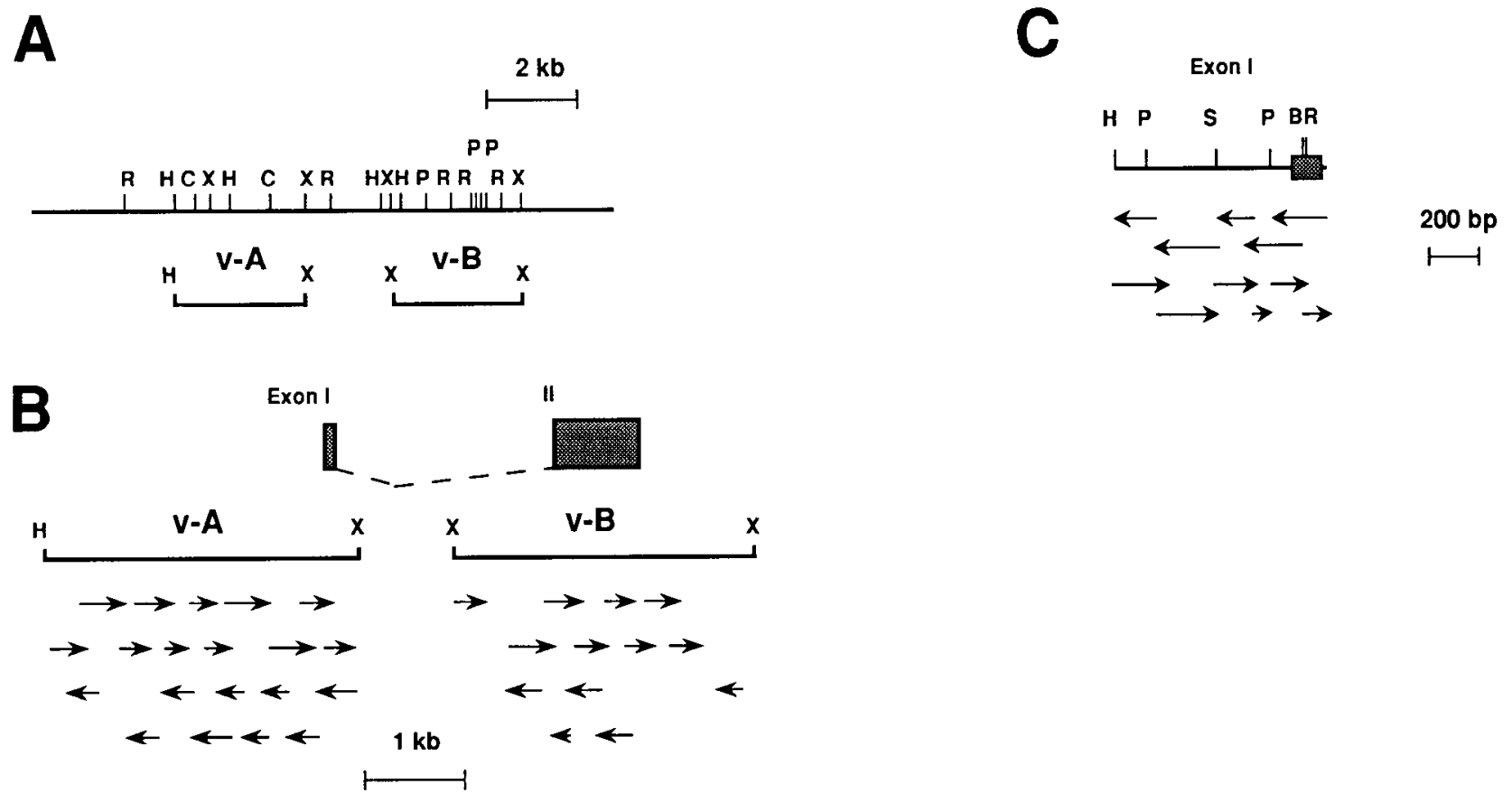

Figure 4. Restriction maps and sequencing strategies. $A$, Partial restriction map of the phage lambda EMBL 4 clone V6 that encompasses approximately $13 \mathrm{~kb}$ of $D$. virilis DNA. $B$, Two regions of the V6 clone ( $v-A$ and $v-B$ ) chosen for subcloning are highlighted; the sequencing strategy is indicated. For the case of the v-B subclone, only those regions that were sequenced on both strands are described. The structure of the virilis FMRFamide gene, based on the sequence similarities to the FMRFamide gene of $D$. melanogaster, is indicated at the top. The $3^{\prime}$ end of exon II cannot be accurately surmised from sequence analysis. The dashed line indicates the presumed splicing strategy. $C$, Partial restriction map and sequencing strategy used to study the portion of the $D$. melanogaster gene (from a lambda Charon $4 A$ phage clone) that contains the first exon and regions upstream. Restriction enzyme abbreviations are as follows: $C$, Hinc II; $H$, Hind III; $P$, Pst I; $R$, Eco RI; $S$, Sma I; $X$, Xba I.

Figure 2. Immunocytochemical staining of the central and enteric nervous systems of $D$. melanogaster and of $D$. virilis using an anti-FMRFamide antibody. Immunoreactive neurons were visualized within the CNS and gut of third instar larvae in wholemount. $A$, The MP1 (triangles) and MP2 (curved arrows) neurons in the dorsal protocerebrum of the CNS. The unmarked cells in the anterior regions of the brain are SP cells. $B$, The LP1 (thin arrows) and SP (fat arrows) neurons in the ventral and anterior protocerebrum, respectively. Note the greater amount of stained processes within the protocerebrum of virilis. $C$, Cells within the oesophagic ganglion of the gut (open arrows). D, The TV1-3 and SE2 neurons (arrowheads) within the ventral region of the thoracic and subesophageal neuromeres of the ventral nerve cord. $E$, The At 1 neurons within the terminal abdominal ganglion (solid arrow). Note the immunoreactive connectives within the ventral nerve cord. Abbreviations based on nomenclature of White et al., (1986); mel, melanogaster; vir, virilis. 
1934 Taghert and Schneider - Neuropeptide Gene Evolution

TGACGGAGTGCGAACGTTCATATACATCA

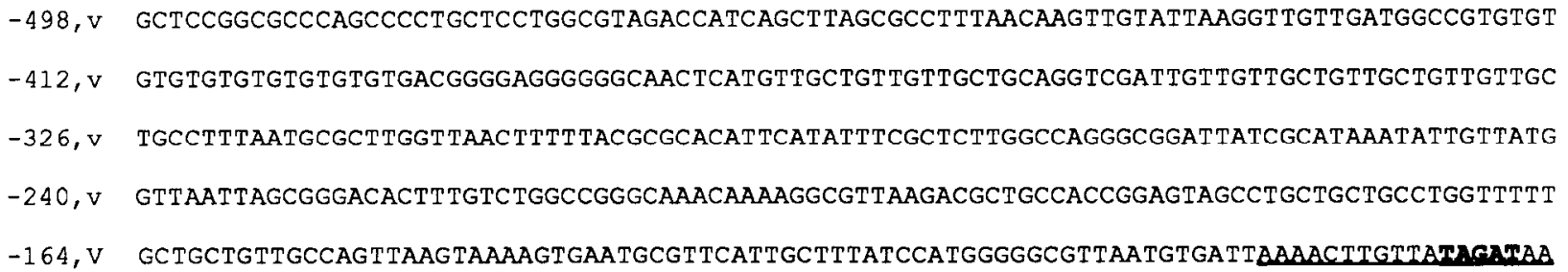

$-83, m$

AAAAGTTGCAAWAGAMACGCGAGATGCCGCCGCCTCAMNMTATCCTGCCGTCACTCCAT TCT TATCC

$-78, v$ IGCGGCAAGTGATTTAGTCAACACCTCAMANTATGTTCAATTTCTCCCTCTCTCCCTCCCTTTCACTCCATCTCAGCACCTTCCA

$+1, \mathrm{v}$

Met Gly Ile Ala Leu Met phe Leu Leu Ala Leu Tyr Gln Met Gln Ser Ala Ile His Ser Glu

$+9, v$ ATC ATG GGC ATA GCA CTG ATG TTC CTG CTG GCC CTC TAC CAG ATG CAG TCG GCC ATC CAT AGC GAG

Ile Ile Asp Thr pro Asn Tyr Ala Gly --- Asn Ser Leu Gln Asp Thr Asp Ser Glu Val Ser Pro

69,m ATC ATC GAT ACG CCC AAC TAT GCG GGC --- AAC TCG TTG CAG GAC ACT GAC TCC GAG GTG AGT CCA

$75, v$ ATT ATT GAG ACG CCA TCC AGC TAT AAT GAT AAC TCG CTG CTG GAG GCA GCT GCG GAG GAG CCC AAT

* * Glu * * Ser Ser Tyr Asn Asp * * * Leu Glu Ala Ala Ala * Glu Pro Asn

Ser Gln Asp Asn Asp Leu Val Asp Ala Leu Leu Gly Asn Asp Gln ...

109, m TCG CAG GAC AAT GAC CTG GTA GAT GCA CTG CTC GGC AAC GAT CAG --- --- --- -- --- --- --

$141, V$ TCG AGA GCC ACC GCG TCT GAG TCG GAT CTG CTG GAT GGA CTG ATG AGC ACC GAT AAT CCC AAT CCG

* Arg Ala Thr Ala ser Glu ser Asp * * Asp Gly Leu Met Ser Thr Asp Asn Pro Asn Pro

$21, \mathrm{~m}$

$21, v$

$42, \mathrm{~m}$

$44, v$

$57, \mathrm{~m}$

$66, v$

Thr Glu Arg Ala Glu Leu Glu Phe Arg His Pro Ile Ser Val Ile Gly Ile Asp Tyr Ser Lys Asn $175, \mathrm{~m}$ ACC GAG AGG GCG GAG CTG GAG TTC CGG CAC CCC ATC TCT GTG ATT GGC ATC GAC TAC TCG AAG AAC $207, v$ GAG CAG CAA ACC GAA CTG GAG TTT CGC TAT CCG ATC TCG GCC ATT GGC ATT GGT TAT GCC AAG AAT

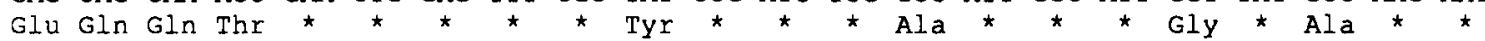

Ala Val Val Leu His Phe Gln Lys His Gly Arg Lys Pro Arg Tyr Lys Tyr Asp Pro Glu Leu Glu $241, \mathrm{~m}$ GCC GTG GTG CTG CAC TTC CAG AAA CAC GGC CGG AAA CCG CGC TAC AAG TAC GAT CCC GAG CTG GAG 273,v TCG GTG GTG TTG CGT TTC CAG AAG CAC GCG CGC AAA CAG AAC TTC AAG TAC GAT CCG GAC TAC GAG Ser * * * Arg * * * * Ala * * Gln Asn Phe * * $*$ Asp Tyr

M1

Ala Lys Arg Arg Ser Val Gln Asp Asn Phe Met His Phe Gly Lys Arg Gln Ala Glu Gln Leu Pro $307, \mathrm{~m}$ GCC AAG CGA AGG TCC GTG CAC GAC AAC TTC ATG CAC TTC GGC AAG AGG CAG GCG GAG CAG CTG CCA $339, v$ ATG AAG CGC AAG TCG CTA CAG GAC AAT TTC ATG CAC TTT GGC AAG CGG CAG GCG GAG CAG CTG CCT

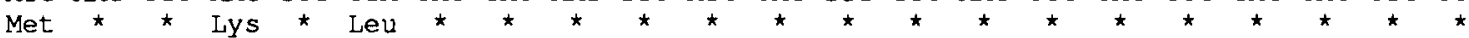
$\mathbf{v 1}$

Pro Glu Gly Ser Tyr Ala Gly Ser Asp Glu Leu Glu Gly Met Ala Lys Arg Ala Ala Met Asp Arg 373,m CCG GAG GGC AGC TAT GCT GGA TCC GAT GAA CTG GAG GGC ATG GCC AAG CGA GCA GCT ATG GAT CGG $405, v$ CAG GCA ACT GGA CCC GGC TAC TAT -- - - - - GAG -- GCG ATC AAG CGC GCC GCC ATG GAT CGC

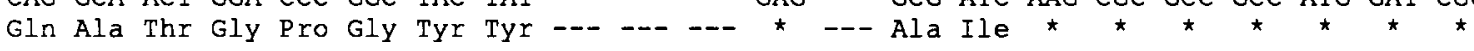

M2A $\mathbf{M B}$

Tyr Gly Arg Asp Pro Lys Gln Asp Phe Met Arg Phe Gly Arg Asp Pro Lys Gln Asp Phe Met Arg 439,m TAT $459, \mathrm{~V}$ TAC GGA CGC GAT CCC AAG CAG GAC TTT ATG CGT TTC GGG CGT GCT CCG CCT TCG GAC TTT ATG CGC $\mathbf{2} \mathbf{x}$ Ala
V2B

Figure 5. DNA sequences encoding the FMRFamide gene compared between $D$. melanogaster and $D$. virilis. The sequences are aligned at the initiator methionine and the numbering begins at this residue. To the left is indicated the bp numbering; to the right, amino acid numbering. Lowercase $m$ and $v$ stand for melanogaster and virilis, respectively. Within the open reading frames, deduced protein sequences are presented above (in the case of melanogaster) or below the DNA sequence (in the case of virilis). Asterisks indicate conserved amino acid residues; dashes indicate gaps introduced so as to align the sequences at clear regions of homology. In boldface, peptide names (e.g., $M I$ and $V I$ ) indicate the positions of

10 FMRFamide-like peptides that are similarly separated by 2 spacer regions. In both species, each of these peptides is extended in the $\mathrm{N}$-terminal direction by $3-5$ amino acids.

Sequence conservation in the FMRFamide-related peptides is illustrated in Figure 6. The sequence of the first FMRFamidelike peptide ( $\mathrm{m} 1$ and $\mathrm{vl}$ ) is highly conserved: these peptides have a single amino acid difference in the $\mathrm{N}$-terminal extension sequence, and in both peptides, His is substituted for $\mathrm{Arg}$ at the 
Phe Gly Arg Asp Pro Lys Gln Asp phe Met Arg phe Gly Arg Asp Pro Lys Gln Asp Phe Met Arg 505,m TTT GGC AGG GAT CCA AAG CAG GAC TTC ATG AGA TTC GGT CGG GAT CCC AAG CAG GAT TTC ATG AGA 525, V TTC GGA CGT GCA CCC TCG -. GAC TTT ATG CGT TTC GGA CGC GAT CCC AGC CAG GAT TTC ATG CGC

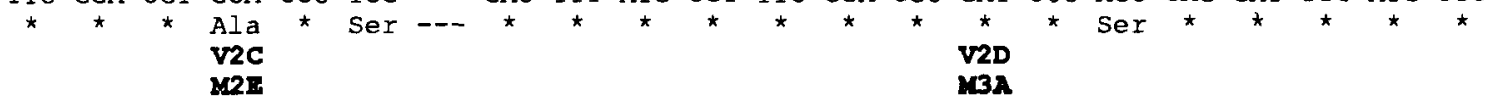

Phe Gly Arg Asp Pro Lys Gln Asp Phe Met Arg Phe Gly Arg Thr Pro Ala Glu Asp Phe Met Arg $571, m$ TTC GGT CGA GAT CCC AAG CAG GAT TTC ATG AGG TTT GGA CGC ACT CCG GCT GAG GAT TTC ATG AGG 588 , $v$ TTC GGG CGC $\ldots \ldots$

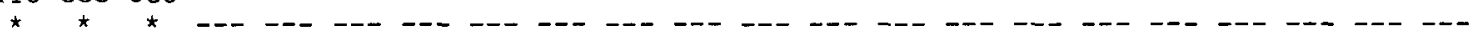

M3B

Phe Gly Arg Thr Pro Ala Glu Asp Phe Met Arg Phe Gly Arg Ser Asp Asn Phe Met Arg Phe Gly 637, m TTC GGA CGC ACT CCG GCG GAG GAC TTC ATG AGG TTC GGA CGC TCC GAC AAT TTC ATG CGC TTC GGA $597, \mathrm{v}$ - - - - V4

\section{M5}

Arg Ser -- -- Pro His Glu Glu Leu Arg Ser Pro Lys Gln Asp Phe Met Arg Phe Gly Arg Pro 697,m CGC AGT -.- -.- CCC CAC GAG GAG CTT CGC AGT CCC AAA CAG GAT TTC ATG CGA TTC GGT CGC CCG $621, v$ AGG AAC CTG AAC TTT CAC GAG GAG CTG CGC AGT CCC AAA CAG GAT TTC ATG CGT TTC GGT CGC CCG

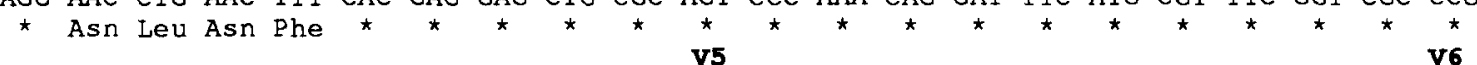

Asp Asn Phe Met Arg Phe Gly Arg ser Ala Pro Gln Asp phe Val Arg ser Gly Lys Met Asp ser $763, \mathrm{~m}$ GAC AAC TTC ATG CGC TTC GGG CGT TCC GCT CCG CAG GAT TTT GTG CGC TCC GGG AAG ATG GAC TCA $687, v$ GAC AAT TTC ATG CGC TTC GGC CGA TCC GCG CCC ACA GAA TTC GAG CGT AAT GGC AAA ATG GAC TCG

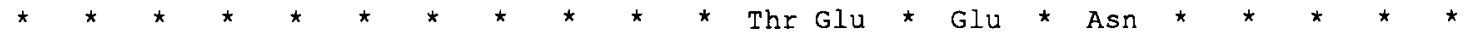

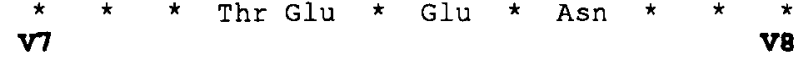

Asn Phe Ile Arg Phe Gly Lys --- Ser Leu Lys Pro Ala Ala Pro Glu Ser Lys Pro Val Lys Ser 826, m AAC TTC ATT CGA TTC GGT AAG --- AGC TTA AAG CCG GCG GCT CCC GAG TCC AAG CCA GTC AAG TCC 753,v AAC TTC ATG CGC TTT GGC AAG AGA TCA GGT GTA ATG GCC AAA TTG ACC AAA TCC CAG CTG CAG CAA * * Met * * * * Arg * Gly Val Met * Lys leu Thr lys Ser Gln Leu Gin Gin

Asn Gln Gly Asn Pro Gly Glu Arg ser pro Val Asp Lys Ala Met Thr Glu Leu Phe Lys Lys Gin 892, m AAT CAA GGC AAC CCA GGC GAA CGC AGT CCA GTG GAC AAG GCC ATG ACG GAG CTG TTC AAG AAA CAG $819, \mathrm{~V}$ AAC AAA TTG ACA ACT GCC GAT GGC AAG CAG CAG CCA GCC GAG GAG GGC AAT CCC ACG GAC AAG GCC * Lys Leu Thr Thr Ala Asp Gly Lys Gln Gln Pro Ala Glu Glu Gly Asn Pro Thr Asp * Ala

Glu Leu Gin Asp Gin Gln val Lys Asn Gly Ala Gln Ala Thr Thr Thr Gln Asp Gly Ser Val Glu 958, m GAG CTG CAG GAT CAG CAG GTG AAG AAC GGC GCA CAG GCG ACC ACC ACG CAG GAT GGG AGT GTG GAA 885,v ATC TCG ATG CTA TTC AAT AAG CAC CAG CAG CAG CAG CAG CAG CAG CAG GGG CAG AGG CTG CAG CAG Ile Ser Met Leu Phe Asn Lys His Gin Gin Gin Gln Gin Gin Gin Gin Giy Gin Arg Leu Gin Gin

Gln Asp Gln Phe Phe Gly Gln srop

1026, m CAG GAC CAG TTC TTC GGC CAG TGA GGTAGTCCTGCGGGACGCCTCCTTGTAAATAGATATGGACAAATGTACGCAAGG 951,v GAA GAC CGA CAG CAG ATG AAG AGC AGC GCA GAG CAG AAC AAC TTG GAG GAA GCC AGC GTG GAG CAG Glu * Arg Gln Gln Met Lys Ser Ser Ala Glu Gin Asn Asn Leu glu glu Ala Ser Val Glu Gln

1100, m ATCTAAATTGATATACGTATATAACCCACTCCTCACACGAACTCCTGACTTATGCCTGAACTATGAATTTTTAATGAATGGGCTGGA $1017, \mathrm{~V}$ TTC TAT GAG CCA TAG ATTCTACCGCGCACAGCACACTGTAAATATAAATTGGCCAAAAAAACCGAACACTATGATAATTTG Phe TYr Glu Pro stop 341

1185, m TAAAAATTCACCGTGCTT TGAAGTTCTTATCTATAAATATATCTAGTGTAATATTGAAGAAATTGAAATTGGCGTGAATAAAATCCT $1103, \mathrm{~V}$ TACTTAACACTATGTATGTATGTACTTAAACGCATTATAGACATIGCAGAAGAAATTTAAAAAAGGAAAAAAAAAAACGTAATTTGA

1276, m GTGGCAACATTTTAAATAAAGATTGCTTTACTGTAAATTATGGCGC

$1190, v$ ATTTTAATGGGGCTGGAITAAAAATTCACCACGCTTTGATCTGATCATAGAAAACAAAAGAAAAAAAAGTAGAAAACTCT

the FMRFamide-like neuropeptide-coding regions. In the intronic region, 2 sequences that display homology between species, and that resemble consensus $3^{\prime}$ intron splice signals, are indicated by boldface and underlining. In the $3^{\prime}$ untranslated regions, potential polyadenylation signals are indicated by underlines. The $3^{\prime}$ untranslated region of melanogaster ends at a point where, in the cDNA, a poly A tract begins (Schneider and Taghert, 1988). These sequences have been submitted to Genbank: accession numbers M32640, melanogaster, and M32643, virilis.

penultimate residue. In virilis, the first spacer region is shorter and conserved only at its ends. The second set of FMRFamidelike peptides in melanogaster contains 8 peptides: 5 are tandem repeats of DPKQDFMRFG $(\mathrm{m} 2 \mathrm{a}-\mathrm{m} 2 \mathrm{e})$. The following 2 have the extension sequence TPAED- (m3a, m3b), and the last (m4) has the extension SDN-. In the case of virilis, there are only 5 peptides in this set; the first ( $v 2 a$ ) and last (v4) are precisely conserved. The intervening 3 appear similar to DPKQDFMRFG 
Figure 6. A comparison of the structures of the deduced precursor proteins encoded by the FMRFamide genes of $D$. virilis and $D$. melanogaster. Top, Schematic diagrams of the proteins placed with the initiator methionines in register. The presumed signal seyuences are indicated by lightly filled boxes at the extreme left-hand ends. Dark boxes within each protein indicate positions of deduced FMRFamidecontaining peptides, $v 1-8$ and $\mathrm{m} 1-8 \mathrm{re}-$ spectively. Bottom, Direct comparison of the peptides according to the registration of the proteins indicated above. The peptide names are boxed and are located at the amino-terminus of each peptide; note that in this imposed registration, peptides $\mathrm{m} 2 \mathrm{e}, \mathrm{m} 3 \mathrm{a}$, and $\mathrm{m} 3 \mathrm{~b}$ lack counterparts in the virilis precursor. The peptide sequences are given in single-letter code and in boldface and are followed in roman text by glycine and basic residues, which, although these are not likely to be present in the mature processed peptides, are included here for the purpose of direct comparison.

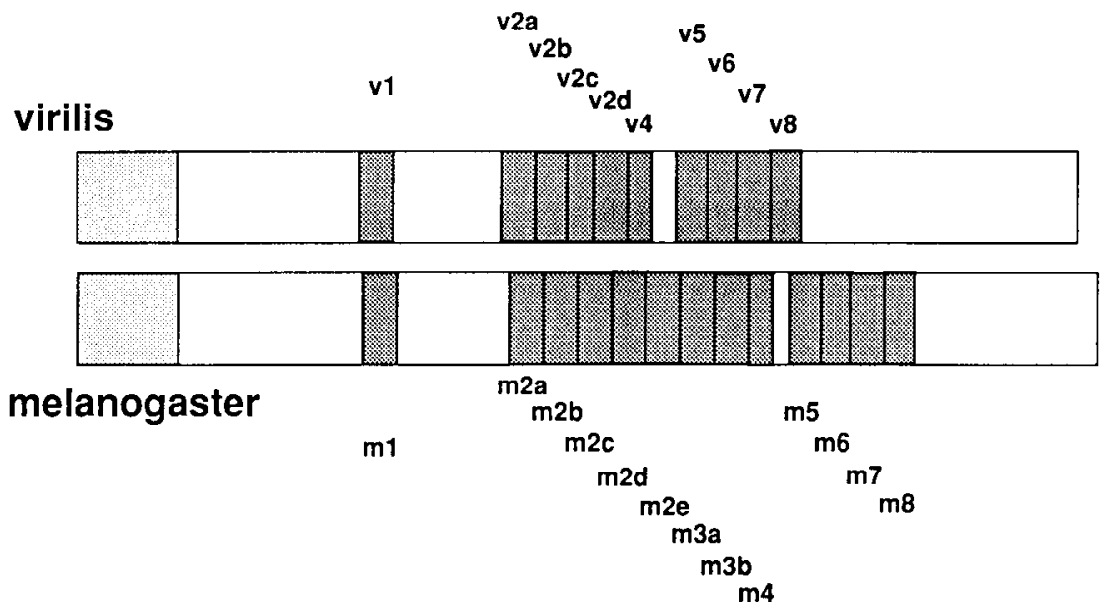

SLKQDFMHFGKR m1 SVKQDFMHFGKR

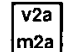

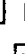

DPKODFMRFGR

v2b APPSDFMRFGR

m2b DPKQDFMRFGR

v2c APSDFMRFGR

m2c DPKQDFMRFGR

V2d DPSQDFMRFGR

m2d DPKQDFMRFGR

m22 DPKQDFMRFGR

m3a TPAEDFMRFGR

m3b TPAEDFMRFGR

v4 SDNFMRFGR

m4 SDNFMRFGR but differ at 1-3 residues. The final set of FMRFamide-containing peptides in the melanogaster precursor $(\mathrm{m} 5-\mathrm{m} 8)$ consists of 4 peptides each with a unique extension sequence. A very comparable set of peptides exists in the virilis precursor (v5$\mathrm{v} 8$ ), but with 2 notable sequence differences: the third peptide of this set in the melanogaster precursor ( $\mathrm{m} 7$ in Fig. 6) is the most degenerate FMRF-like sequence, FVRS. Likewise, in the virilis precursor peptide, $\mathrm{v} 7$ is similarly degenerate at the same residues, but with different amino acid substitutions, FERN. In addition, peptide $\mathrm{m} 8$ in melanogaster, which ended in -FIRF, was an -FMRF peptide in virilis (v8).

The degree of sequence conservation outside of the regions containing FMRFamide-like peptides varied greatly; the precursors have approximately $59 \%$ amino acid identity. Plots of the percentage identity between precursors at both the amino acid and nucleic acid levels are shown in Figure 7 . The region from the end of the hydrophobic signal peptide to the first FMRFamide-like peptide (peptide 1, Fig. 6) is highly divergent for the first $\sim 50 \mathrm{AAs}$, then displays increasing identity in the $\sim 40$ AAs preceding the first FMRFamide-like peptide. The highest conservation (besides the region of the hydrophobic leader sequence) is found in the 3 regions encoding FMRFamide-like peptides; the degrees of identity fall precipitously immediately following peptide 8 . The C-terminal region of the virilis precursor is $18 \mathrm{AAs}$ longer than is that of melanogaster. It is noteworthy that all single, di-, and tribasic AA residues, the pre- sumed cleavage sites for the liberation of the FMRFamide-like peptides, are preserved between the 2 species. The 2 exceptions include a conservative change $\mathrm{Arg}$ to $L y s$ (immediately preceding the v1 peptide) and the addition of an Arg to form Lys-Arg immediately following peptide $\mathrm{v} 8$.

In summary, 5 regions of sequence conservation within the neuropeptide precursor are evident: the putative signal peptide region, a $\sim 40 \mathrm{AA}$ region in the $\mathrm{N}$-terminal portion of the precursor that immediately precedes the first FMRFamide-like peptide, and finally the 3 groups of FMRFamide-containing neuropeptides.

\section{Homologies in the 5' exon and upstream regions}

We compared the DNA sequences of regions that are $5^{\prime}$ to the mRNA start sites of the 2 species. A total of $\sim 1.2 \mathrm{~kb}$ of $D$. melanogaster DNA and $1.8 \mathrm{~kb}$ of $D$. virilis DNA was analyzed (Fig. 8). Whereas the start site in melanogaster has been defined by Northern blot analysis, primer extension, and nuclease protection assays (Schneider and Taghert, unpublished observations), the interpretation of the virilis neuropeptide gene structure is based solely on sequence comparisons. In virilis, the sequence of exon I is largely divergent: sequence conservation is limited to the first 34 bases, of which 26 are conserved. This conserved region is part of a larger $68 \mathrm{bp}$ region of homology (\#18 in Fig. 9) that begins with a sequence resembling the canonical TATA box. In total this region is conserved at 56 of 68 


\section{D. virilis}

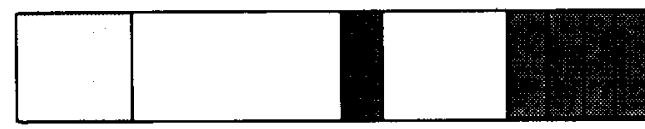

-... II

\section{D. melanogaster}

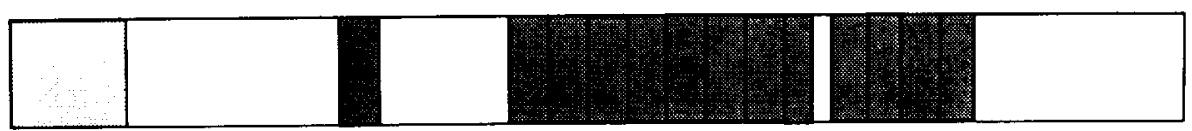

\section{Percent amino acid identity}
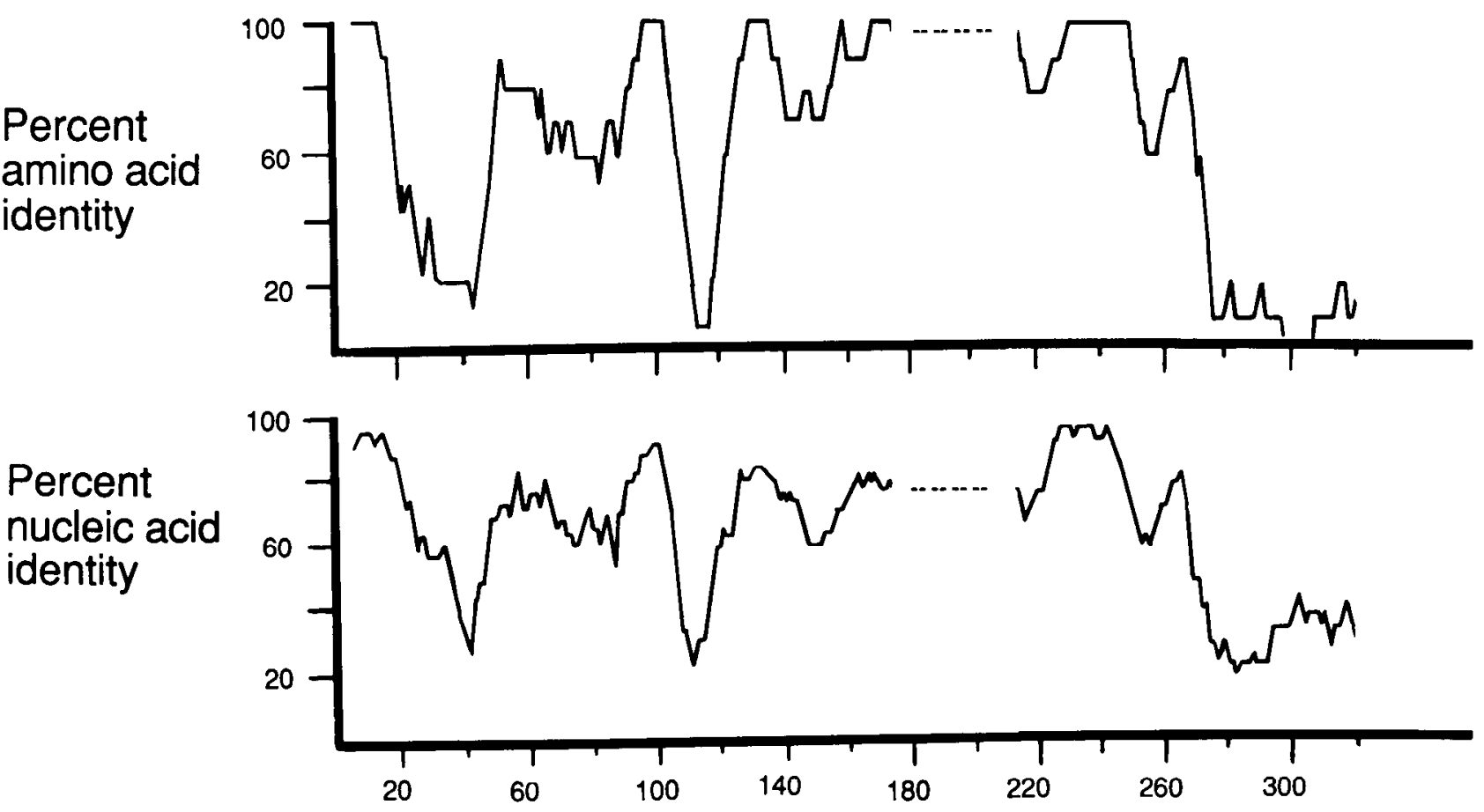

\section{residue number}

Figure 7. Polyprotein precursors containing FMRFamide-like peptides from $D$. virilis and $D$. melanogaster presented schematically along with amino acid and nucleic acid identity plots. The signal sequences are lightly shaded and aligned at the extreme amino-terminus. The FMRFamidelike peptides are shaded darkly. The virilis precursor is interrupted so as to align C-terminal regions more precisely with homologous regions of the melanogaster precursor. $Y$-axis, percentage identity; $x$-axis, amino acid position along the precursors. The plots were generated as follows: for the amino acid identity plot, beginning at position \#5, a run of 10 consecutive (nos. $1-10$ ) was compared between the 2 precursors and the percentage (the number of conserved residues $\times 10$ ) was determined. The determination was then repeated for the next 10 consecutive residues (from nos. $2-11$ ) to define the identity value at residue 6 . This procedure was repeated through all residues up to the fifth from the $C$-terminal end of the precursor, and the percentages were graphed with the percentage identity plotted along the $y$-axis and the position along the precursor serving as the $x$-axis. For the nucleotide identity plot, a similar stratcgy was employed: for each amino acid position, the corresponding 30 nucleotides (encoding the 10 respective amino acids) were compared. The percentage nucleic acid identity was determined for each amino acid position and plotted as for the amino acid identity. Apparent deletions and/or insertions were identified by eye, and therefore the following residues were not considered in the homology analysis: melanogaster, nos. 133-136, 174, and 193-224 (shown as a gap in the figure); virilis, 60-66, 242-243, and 295.

residues. Following this region, no significant homology is observed through the rest of exon I (72 bp). The melanogaster exon I ends at $+106 \mathrm{bp}$, as mapped by genomic DNA sequencing and a nuclease protection assay; this splice junction is: A-G-/ G-T-G-A-G-T (where the slash denotes the splice site) and it matches the consensus sequence (A-G-/G-T-A-A-G-T, derived by Padgett et al., 1986). A conserved sequence occurs in virilis at +170 bp (Fig. 8), because of which, we propose that exon I is slightly larger in this species. In neither species does exon I contain an ATG codon to initiate an open reading frame; hence in both species, the protein is encoded completely within exon II. Upstream of the TATA box region, DNA sequences were markedly divergent, but 17 small regions of sequence conservation were found. In all the regions that are noted in Figure 8, the sequences are at least $80 \%$ conserved. The longest such region (\#9) is $51 \mathrm{bp}$ long with 2 mismatches. The relative order of the homologous regions between the 2 species (Fig. 9) is roughly comparable, although in virilis they spanned a region that is $\sim 1 / 3$ longer and 2 regions are displaced (\#8 and 17). The $\sim 2 \mathrm{kB}$ of upstream DNA in virilis was marked by the inclusion 


\section{$(-1686) 1$}

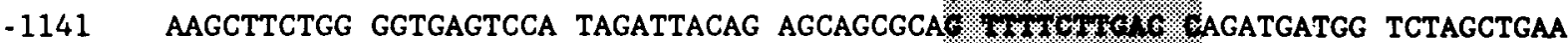
$2(-1668)$

$2^{(-1668)} \%$

-1071 CTATTTTTAA CTGGGCGATT GGCACACGAC TTGGCCTGGT CATCAAACTC AAGCCAAGA $\% \% \%$

- 1001 ACTAGTCTgC CCTTATCACA TTGCCTTCTA ATTCGTTTTC ATTTTCGATT TTCGCATCTA CTTATGCTAA

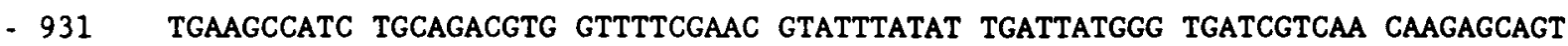

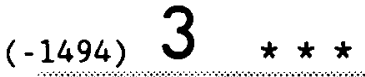

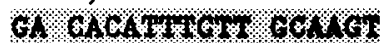

- 861 GGACACCCAA TAAACCTGTC CAAAACCCGN EACAT\% O10\% \%\%.G\%CATG CGTGGTGGAC AATAGCCAAA

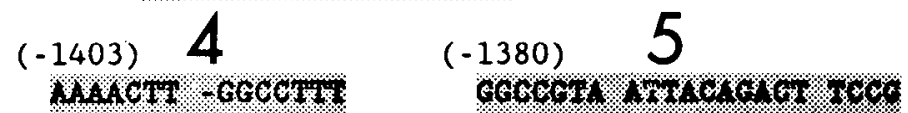

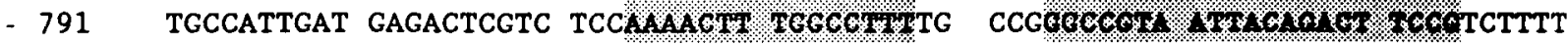

- 721 GAACAGTTTT TTCAGCCCCA CCCAAGAGTC GAGTCTTGAA AAGCTGGCTG GGATGGGGTG GTTTCGGGTG

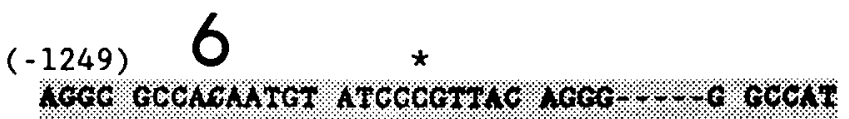

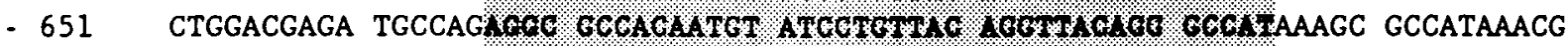

$$
\begin{gathered}
(-1199) * 7 * * * * \\
\text { 6000\% }
\end{gathered}
$$

- 581 CCGCGACGGC AATGGCAMT TATAAGGCAT AGGGAOAGOT IGTCGATCCA CTGGCTAGAA GGCTAATTGG

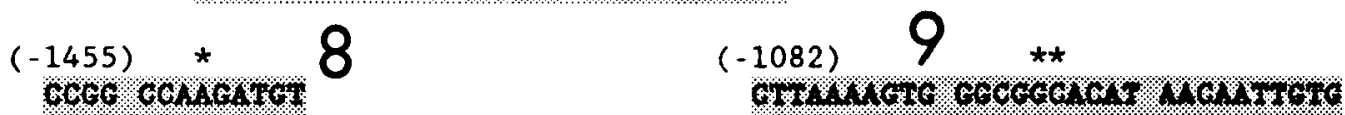

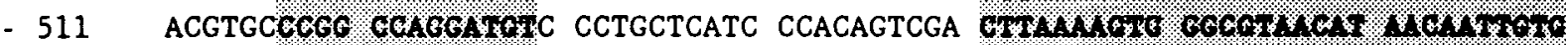

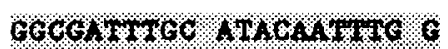

$$
(-1004) * 10 *
$$

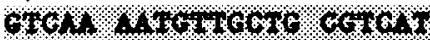

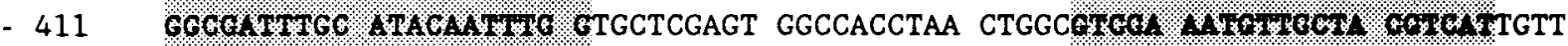

- 371 GCTGCCCCTC GTGCTTCTTG GCTAATAAGT CAGCATGAAT GCGGTCTGTG TTTTGGCCTT TTGTCCCGCT

$$
(-775)
$$

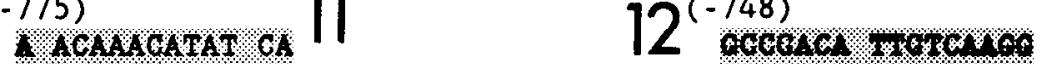

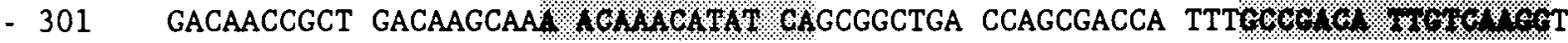

- 231 TTTTTTTTCA GCCCCGAATA CACCTGCTAA TCTGTGGTGg TGACTAGCGC GCTCGgAagG CAGAAAAAAC

$$
(-248) \mid 3(-217) * \quad 14
$$

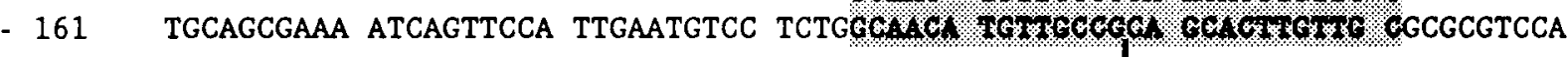

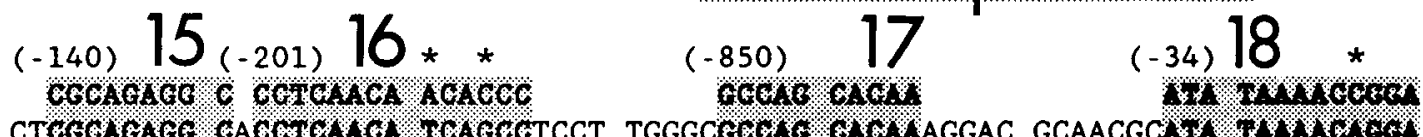

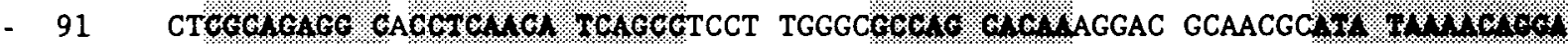

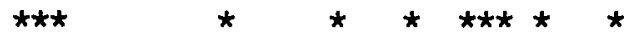

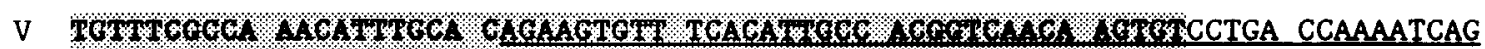

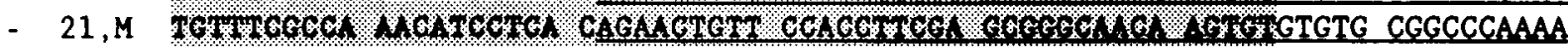

V GTAGAAGAAG AACCACACGA GTGGCCAGTG AAAAGTGTTT TAAAATTTCC CATTTCCCAA CGGAATGTCG

$+50 \mathrm{M}$ GGATCCCCAG ACCTTCGAAT TCACTCTAGT TTCCTAGTAA GGGGACAGGT TTCAGAGGTG AGTGCCATGC MEL, EXON I: SPLICE

$\mathrm{V}$ ATTTGATTGC ATTGCAATAT TCGTATAATT TTAAATATTT GAAAAAAAAG GTGAGT

$+120 \mathrm{M}$ GAAAAGTGTG

VIR, EXON I: SPLICE 


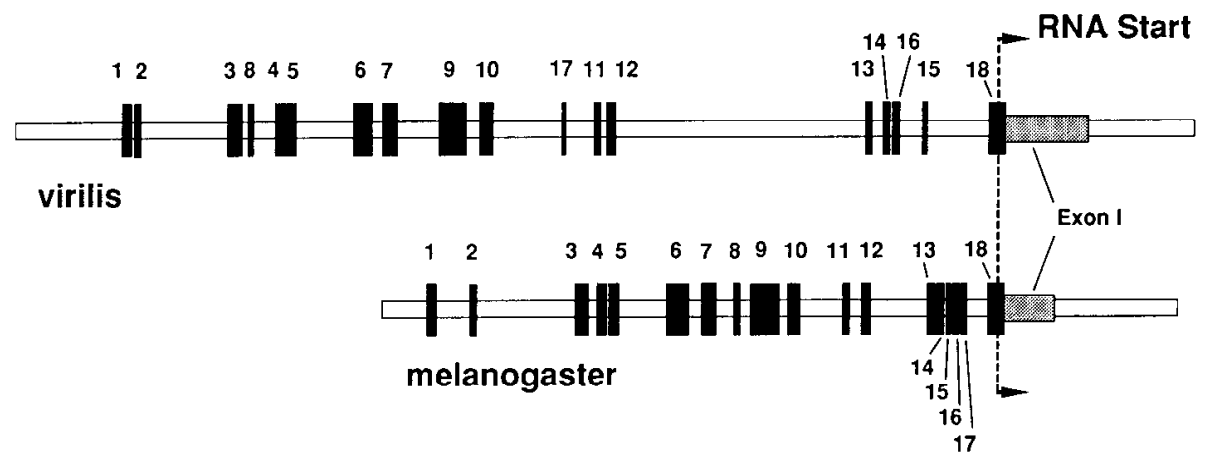

$-1800$

$-1800$

$-1600$

$-1400$

.1200

$-1000$

$-800$

$-600$

$-400$

$-200$
Figure 9. Map of the conserved regions that are $5^{\prime}$ to the RNA start site (dotted line) of the FMRFamide gene in $D$. melanogaster and $D$. virilis. These regions are 9-68 bp in length and in $D$. melanogaster are consecutively numbered $1-18$ beginning with the region most distal to the start site. Region 18 begins with a canonical TATA box sequence and ends just after the start site. Note that exon I (light shading) is larger in virilis and does not show significant sequence similarity except in the vicinity of the RNA start site. of numerous repetitive sequences: tracts consisting of poly $A$ and dinucleotide (TA or CA) repeats.

\section{Discussion}

We have adopted the strategy of interspecific comparison of DNA sequences in hopes of identifying conserved regions of a neuropeptide gene and its regulatory elements. Sequence conservation may imply a correspondent functional conservation. This assumption has been borne out in the cases both of promoter elements [e.g., the Dopa decarboxylase gene promoter of Drosophila (Johnson et al., 1989)] and of protein-coding regions [e.g., the homeodomains (Bodner et al., 1988; Ingraham et al., 1988; Way and Chalfie, 1988)]. The conserved regions of the Drosophila FMRFamide neuropeptide gene, and its upstream regions, provide a framework on which to create testable hypotheses concerning neuropeptide biosynthesis, function, and gene regulation.

\section{Gene organization, transcription, and translation}

Each species of Drosophila examined contained a single gene that hybridized to the melanogaster ncuropeptide gene (Fig. 1). This result suggests that the gene has retained functional importance for this group of animals. Direct comparisons of this neuropeptide gene revealed that its organization in $D$. virilis is similar to that of $D$. melanogaster. A single large intron separates a small exon I from the larger exon II; in both species, the latter completely encodes the deduced neuropeptide precursor protein. Neither the $5^{\prime}$ nor the $3^{\prime}$ boundary of the neuropeptide gene intron is perfectly conserved, although sequence conservation can be noted at the $3^{\prime}$ end of the intron (Fig. 5). The available evidence from the study of FMRFamide gene expression in $D$. melanogaster indicates that there is only one predominant transcript throughout all stages of postembryonic development (Schneider and Taghert, 1988, and unpublished observations; Schneider et al., unpublished observations) and thus the potential for alternative splicing appears slight.
Regulation of neuropeptide gene expression may also occur at the translational level. In a great majority of genes analyzed, the $5^{\prime}$ untranslated regions of mRNAs are short (i.e., < 160 bases in length), contain no AUGs upstream of the translation initiation sitc, and show little conservation between species (Kozak, 1984, 1986). The Drosophila FMRFamide neuropeptide gene conforms to this generalization, with the only conserved sequences of the first exon existing in a short region that includes the transcription start site. Certain Drosophila segmentation genes (Mueller and Hinnebusch, 1986; Wilde and Akam, 1987; Tautz, 1988) and heat shock genes (McGarry and Lindquist, 1985) display translational regulation, in part controlled by sequences in long untranslated leaders, that are evolutionarily conserved. Because the untranslated leader sequence of the neuropeptide mRNA does not display these properties, we think it unlikely that it is subject to similar forms of translational control.

\section{The neuropeptide precursors}

Although the virilis precursor contains 3 fewer FMRFamidelike peptides, it is nevertheless of the same approximate size as that of melanogaster, 339 vs 347 amino acids, respectively. This conservation of length is achieved by an increased distance between the last FMRFamide-like peptide and the stop codon, a region that is composed almost exclusively of divergent sequence. This observation suggests that precursor size (independent of sequence) may be a critical feature of the protein for aspects of its posttranslational processing and/or intragranular packaging. We propose that signal cleavage occurs after residue \#17 (Ala): this assignment is based on the similarity of this region to a consensus previously proposed for signal splice sites (von Heijne, 1983), the fact that it is immediately followed by charged residues (Haeutple et al., 1989), and that it shows a high degree of conservation between species (Fig. 5; for comparison to other insect signal sequences, see Lidholm et al., 1987). An evolutionary pressure to conserve the entire signal sequence is implied from the precursor structures: the first 23

\footnotetext{
Figure 8. Nucleotide sequences of exon I and regions of homology in the area immediately $5^{\prime}$ to the FMRFamide gene. The melanogaster sequence is presented in its entirety from -1200 to $+200 \mathrm{bp}$ relative to the mRNA start site ( +1 , numbers at left; $M$, melanogaster; $V$, virilis). The sequences of exon I are underlined for both species. Arrowheads mark the 3' end of each exon I (note their different sizes), at which a conserved splice site sequence is displayed in bold. Boldface sequences within gray backgrounds indicate regions of significant nucleotide conservation between melanogaster and virilis. The regions are numbered 1-18 consecutively, and their relative positions in the 2 species are diagramed in Figure 9 . The $D$. virilis sequences are aligned above the corresponding $D$. melanogaster sequences with mismatches marked by asterisks and gaps by dashes. Numbers in parentheses preceding the $D$. virilis sequences indicate their positions relative to the RNA start site of that species. Complete sequences have been submitted to Genbank: accession numbers M32641, melanogaster; M32642, virilis.
} 
amino acids of the 2 proteins are identical. Interspecific comparisons of signal sequences between genes encoding homologous proteins have tended to indicate conservation of overall hydrophobicity but a lack of sequence conservation except at the cleavage site. For example, the signal sequences of rat and human pre-proenkephalin are only $70 \%$ identical (Yoshikawa et al., 1984). The significance of the perfect conservation between the signal sequences in 2 Drosophila species (60-80 million years divergent; Throckmorton, 1975) is uncertain; it may imply a necessity for this region to interact with other specific molecules during neuropeptide biosynthesis, rather than simply to provide a hydrophobic core by which to enter the lumen of the endoplasmic reticulum.

\section{The FMRFamide-like peptides}

The FMRFamide precursor of Drosophila melanogaster contains 13 copies of FMRFamide-like peptides, which present 7 different peptide sequences and which vary in their representation (from unique copies to 5 tandem repeats). To what extent are the differing sequences, copy numbers, and/or positions within the precursor important for neuropeptide biosynthesis or neuropeptide function"? Interspecific comparisons of the preproenkephalin gene of 3 different mammals have shown a strict conscrvation in the scquence, number, and order of the enkephalin and enkephalin-extended peptide forms within the precursors (Rosen et al., 1984; Yoshikawa et al., 1984). The comparison of neuropeptide precursors between the 2 Drosophila species indicates (1) a conservation of the basic organization of peptides within the precursor, (2) variability in peptide copy number, and (3) a limited degree of conservation in peptide sequence.

In both Drosophila precursors, 3 groups of FMRFamide-like peptides are found: peptide 1 , peptides $2-4$, and peptides 5-8 (Fig. 5). These groups are separated by short protein regions that may themselves represent biologically active molecules, although for both spacer regions there has occurred at least partial sequence divergence. Based on the conservation of sequences between the 2 Drosophila species, we suspect that these FMRFamide peptide groups may represent 3 functionally distinct sets. In the case of melanogaster, 3 of the 13 FMRFamidelike peptides differ from the sequence-FMRF, i.e., -FMHF (m 1$)$, -FVRS $(\mathrm{m} 7)$, and -FIRF $(\mathrm{m} 8)$. In the case of virilis, only one of these variations has been conserved: peptide $\mathrm{vl}$ is also an -FMHFamide. Because its extension ( $\mathrm{N}$-terminal extension of -FMRFamide) is also conserved, we suggest that this neuropeptide may represent a functionally distinct molecule. Likewise, the final peptide group ( $\mathrm{m} 5-\mathrm{m} 8$ and $\mathrm{v} 5-\mathrm{v} 8$ ) is highly conserved between the 2 species in both number and extention sequence.

In contrast to the others, the middle group of peptides varies in the number of peptide repeat units and in their sequences. We make 2 inferences from this observation. First, because the extension sequences vary, the physiological roles of these individual peptides may not be intimately coupled to the specific extension sequences that are found. Second, the variation in copy number of peptides in this group (total of 5 vs 8 ) suggests that, while multiple copies of specific peptides may be advantageous, their absolute number is not a critical feature of the precursor. Perhaps only a minimum number is required, and having "extra" copies of peptides $\mathrm{m} 2$ or $\mathrm{m} 3$ may provide the latitude to experiment with new peptide sequences that are free from strong negative selection. Payza (1987) has argued that
FMRFamide and related heptapeptide forms of the snail Helix interact with distinct receptors. Whether the various forms of FMRFamide found in Drosophila also have distinct receptors, as we suggest here, must await experimental analysis. Alternatively, variations in the extension sequences of the FMRFamide-like peptides may represent evolutionary attempts to change degradation rates following release. In the cases of other genes that contain repetitive sequence elements, changes in the copy number are thought to have arisen by unequal crossover events (e.g., Enea et al., 1984; Wiborg et al., 1985; Lee et al., 1988). However, the mechanisms leading to such changes are unknown.

\section{The promoter regions of the neuropeptide gene}

In situ hybridization studies to localize FMRFamide gene transcripts (Schneider et al., 1988; Schneider et al., unpublished observations) suggest large differences in the amount of specific neuropeptide gene expression among different neurons of the CNS. Hence, as is thought the case with a variety of other neuropeptide genes and neurotransmitter-related genes (Rosenfeld et al., 1984; Scheller et al., 1984; Beall and Hirsch, 1987), FMRFamide gene expression in Drosophila appears to be regulated in a precise, cell-specific manner. Conserved sequence elements in the $5^{\prime}$ upstream regions of the FMRFamide gene (Fig. 8) are therefore of interest in that they may represent candidate regulatory elements for the control of gene transcription. Regulatory elements of the neuropeptide gene promoter may control the activation of transcription during development (Bodner et al., 1988; Ingraham et al., 1988), as well as by physiologically induced changes in gene expression (Comb et al., 1986). It is unlikely that the sequence conservation that we observed upstream of the FMRFamide gene represents a contiguous transcription unit because this region lacks a significant open reading frame (data not shown). This possibility can be further discounted because of the irregular spacing of the conserved regions displayed by the 2 species (Fig. 9).

The Dopa decarboxylase gene of Drosophila exhibits a comparable cell-specific pattern ( 150 neurons) of expression. Using germ line transformations, Hirsch and colleagues have identificd scquences within the first -200 bp 5 ' to the gene that are necessary for nervous system-specific expression and sequences in a distal enhancer region, $\sim 1600$ bp upstream that are necessary for cell type-specific expression (Beall and Hirsch, 1987). These upstream regions contain sequences that bind specific proteins from embryonic nuclear extracts (i.e., bind putative regulators of transcription) and these functionally important DNA sequences are highly conserved between the species melanogaster and virilis (Scholnick et al., 1986; Johnson et al., 1989). Likewise, functionally defined promoter elements upstream of the Drosophila hunchback gene [these confer sensitivity to regulation by the bicoid gene (Tautz et al., 1987; Schroeder et al., 1988)] show significant sequence homology between melanogaster and virilis species (Treier et al., 1989). We think it likely, therefore, that the present interspecific comparison provides a reasonable first approximation of the functionally important regions of the FMRFamide neuropeptide gene promoter. Although their exact sequences do not correspond to previously defined cis-acting elements, their sizes and their evolutionary conservation are consistent with possible roles in gene regulation. We hope to test some of the hypotheses derived from this interspecific comparison of neuropeptide genes through the 
use of classical genetic methods and the use of germ line transformation techniques.

\section{References}

Beall CJ, Hirsch J (1987) Regulation of the Drosophila Dopa decarboxylase gene in neuronal and non-neuronal cells. Genes Dev 1:510520.

Benton WD, Davis RW (1977) Screening lambda gt recombinant clones by hybridization to single plaques in situ. Science 196:180-182.

Blackman RK, Meselson M (1986) Inter-specific nucleotide sequence comparisons used to identify regulatory and structural features of the Drosophila hsp82 gene. J Mol Biol 188:499-515.

Bodner M, Castrillo J-L, Theill LE, Deernick T, Ellisman M, Karin M (1988) The pituitary-specific transcription factor GHF-1 is a homeobox-containing protein. Cell 55:505-518.

Boyd PJ, Walker RJ (1985) Actions of the molluscan neuropeptide FMRFamide on neurones in the subesophageal ganglia of the snail Helix aspersa. Comp Biochem Physiol 81C:379-386.

Carroll LS, Carrow GM, Calabrese RL (1986) Localization and release of FMRFamide-like immunoreactivity in the cerebral neuroendocrine system of Manduca sexta. J Exp Biol 126:1-14.

Columbaioni L, Paupardin-Tritsch D, Vidal PP, Gershenfeld HM (1985) The neuropeptide FMRFamide decreases both the $\mathrm{Ca}^{2+}$ conductance and a cyclic $3^{\prime} 5^{\prime}$-adenosine monophosphate-dependent $\mathrm{K}^{+}$conductance in identified molluscan neurons. J Neurosci 5:2533-2538.

Comb M, Birnberg NC, Seaholtz A, Herbert E, Goodman HM (1986) A cyclic AMP- and phorbol ester-inducible DNA element. Nature 323:353-356.

Cottrell GA, Davies NW, Green KA (1984) Multiple actions of a molluscan cardioexcitatory neuropeptide and related peptides on identified Helix neurons. J Physiol (Lond) 365:315-333.

Doble KE, Greenberg MJ (1982) The rectum is sensitive to FMRFamide, the enkephalins and their common analogs. Neuropeptides 2 : 157-167.

Ebberink RHM, Price DA, van Loenhout H, Doble KE, Riehm JP, Geraerts WPM, Greenberg MJ (1987) The brain of Lymnae contains a family of FMRFamide-related peptides. Peptides 8:515-522.

Enea V, Arnot D, Schmidt EC, Cochrane A, Gwadz R, Nussenzweig R (1984) Circumsporozoite gene of Plasmodium cynomolgi (Gombak): cDNA cloning and expression of the repetitive circumsporozoite epitope. Proc Nat Acad Sci USA 81:7520-7524.

Evans PD, Myers C (1986) The modulatory actions of FMRFamide and related peptides on locust skeletal muscle. J Exp Biol 126:403422.

Haeuptle M-T, Flint N, Gough NM, Dobberstein B (1989) A tripartite structure of the signals that determine protein insertion into the endoplasmic reticulum membrane. J Cell Biol 108:1227-1236.

Ingraham HA, Chen R, Mangalam HJ, Elshotz HP, Flynn SE, Lin CR, Simmons DM, Swanson L, Rosenfeld MG (1988) A tissue-specific transcription factor containing a homeo-domain specifies a pituitary phenotype. Cell 55:519-529.

Johnson WA, McCormick CA, Bray SJ, Hirsch J (1989) A neuronspecific enhancer of the Drosophila Dopa decarboxylase gene. Genes Dev (in press).

Keller EB, Noon WA (1985) Intron splicing: a conserved internal signal in introns of Drosophila pre-mRNAs. Nucl Acids Res 13:49714981.

Kozak M (1984) Compilation and analysis of sequences upstream from the translation initiation start site in eukaryotic mRNAs. Nucleic Acids Res 12:857-872.

Kozak M (1986) Point mutations define a sequence flanking the AUG initiator codon that modulates translation by eukaryotic ribosomes. Cell 44:283-292.

Lee H, Simon JA, Lis JT (1988) Structure and expression of ubiquitin genes of Drosophila melanogaster. Mol Cell Biol 8:4727-4735.

Lidholm D-A, Gudmundsson GH, Xanthopoulos KG, Bowman HG (1987) Insect immunity: cDNA clones coding for the precursor forms of cecropins $\mathrm{A}$ and $\mathrm{D}$, antibacterial proteins from Hyalophora cecropia. FEBS Lett 226:8-12.

Mahon AC, Nambu JR, Taussig R, Shyamala M, Roach A, Scheller RH (1985) Structure and expression of the egg-laying hormone gene family in Aplysia. J Neurosci 5:1872-1880.

Maniatis T, Fritsch EF, Sambrook J (1982) Molecular cloning. Cold Spring Harbor, NY: Cold Spring Harbor Press.
McGarry ' IJ, Lindquist S (1985) The preferential translation of Drosophila $h s p 70 \mathrm{mRNA}$ requires sequences in the untranslated leader. Cell 42:903-911.

Mueller PP, Hinnebusch A (1986) Multiple upstream AUG codons mediate translational control of GCN4. Cell 45:201-207.

Muneoka Y, Matsuura M (1985) Effects of the molluscan neuropeptide FMRFamide and the related opioid peptide YGGFMRFamide on Mytilus muscle. Comp Biochem Physiol 81:61-70.

Nambu JR, Scheller RII (1986) Egg-laying hormone genes of Aplysia: evolution of the ELH gene family. I Neurosci 6:2026-2036.

Nambu JR, Murphy-Erdosh C, Andrews PC, Feistner G, Scheller RH (1988) Isolation and characterization of a Drosophila neuropeptide gene. Neuron 1:55-61.

Noda M, Furutani Y, Takahashi $H$, Toyosato $M$, Hirose T, Inayama S, Nakanishi S, Numa S (1982) Cloning and sequence analysis of cDNA for bovine adrenal preproenkephalin. Nature 295:202-206.

Padgett RA, Grabowski PJ, Konarska MM, Seiler S, Sharp PA (1986) Splicing of messenger precursors. Annu Rev Biochem 55:1 119-1 150.

Painter SD (1982) FMRFamide catch contractures of a molluscan smooth muscle: pharmacology, ionic dependence and cyclic nucleotides. J Comp Physiol 148:491-501.

Payza K (1987) FMRFamide receptors in Helix aspersa. Peptides 8: 1065-1074.

Price DA, Greenberg MJ (1977) Structure of a molluscan cardioacceleratory peptide. Science 197:670-671.

Price DA, Cottrell GA, Doble KE, Greenberg MJ, Johrenby W, Lehman HK, Riehm JP (1985) A novel FMRFamide-related peptide in $\mathrm{He}$ lix: pQDPLRFamide. Biol Bull 169:256-266.

Price DA, Davies NW, Doble KE, Greenberg MJ (1987a) The variety and distribution of FMRFamide-related peptides in molluscs. Zool Sci 4:395-410.

Price DA, Cobb CG, Doble KE, Kline JK, Greenberg MJ (1987b) Evidence for a novel FMRFamide-related heptapeptide in the pulmonate snail Siphonaria pectinata. Peptides 8:533-538.

Rosen H, Douglass J, Herbert E (1984) Isolation and characterization of the rat proenkephalin gene. J Biol Chem 259:14309-14313.

Rosenfeld MG, Amara SG, Evans RM (1984) Alternative RNA processing: determining neuronal phenotype. Science 225:1315-1320.

Schaefer M, Picciotto MR, Kreiner T, Khaldany RR, Taussig R, Scheller RH (1985) Aplysia neurons express a gene encoding FMRFamide neuropeptides. Cell 41:457-467.

Scheller RH, Khaldany RR, Kreiner T, Mahon AC, Nambu JR, Schaefer M, Taussig R (1984) Neuropeptides: mediators of behavior in Aplysia. Science 225:1300-1308.

Schneider LE, Taghert PH (1988) Isolation and characterization of a Drosophilagene encoding multiple neuropeptide related to FMRFam-

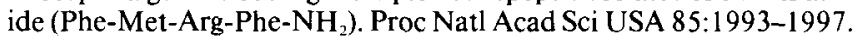

Schneider LE, Taghert PH (1990) Organization and expression of the Drosophila FMRFamide neuropeptide gene. J Biol Chem 265:68906895

Schneider LE, Sun E, Taghert PH (1988) Cellular analysis of a neuropeptide gene in Drosophila melanogaster. Soc Neurosci Abstr 14: 29.

Scholnick SB, Bray SJ, Morgan BA, McCormack CA, Hirsch J (1986) CNS and hypoderm regulatory elements of the Drosophila melanogaster Dopa decarboxylase gene. Science 234:998-1002.

Schroeder C, Tautz D, Seifert E, Jackle H (1988) Differential regulation of the two transcripts from the Drosophila gap segmentation gene hunchback. EMBO J 7:2881-2887.

Taussig R, Scheller RH (1986) The Aplysia FMRFamide gene encodes sequences related to mammalian brain peptides. DNA 5:453-461.

Tautz D (1988) Regulation of the Drosophila segmentation gene hunchback by two maternal morphogenetic centers. Nature 332:281284.

Tautz D, Lehmann R, Schnurch H, Schuh R, Seifert E, Keinlin A, Jones K, Jackle H (1987) Finger protein of novel structure encoded by hunchback, a second member of the gap class of Drosophila segmentation genes. Nature 327:383-389.

Throckmorton, LH (1975) In: Handbook of genetics, Vol 3 (King RC, ed), pp 421-469. New York: Plenum.

Treier M, Pfeifle C, Tautz D (1989) Comparison of the gap segmentation gene hunchback between Drosophila melanogaster and Drosophila virilis reveals novel modes of evolutionary change. EMBO J 8:1517-1525.

Trimmer BA, Kobierski LA, Kravitz EA (1987) Purification and char- 
acterization of FMRFamide-like immunoreactive substances from the lobster nervous system: isolation and sequence analysis of two closely related peptides. J Comp Neurol 266:16-26.

von Hcijnc $G$ (1983) Patterns of amino acids near signal-sequence cleavage sites. EMBO J 5:3021-3027.

Walther C, Scheibe M (1987) FMRF- $\mathrm{NH}_{2}$-like factor from neurohaemal organ modulates neuromuscular transmission in the locust. Neurosci Lett 77:209-214.

Way JC, Chalfie M (1988) mec-3, a homeobox-containing gene that specifies differentiation of the touch receptor neurons in C'. elegans. Cell 54:5-16.

Weiss S. Goldberg JI, Chohan KS, Stell WK, Drummond GI, Lukowiak $\mathrm{K}$ (1984) Evidence for FMRFamide as a neurotransmitter in the gill of Aplysia californica. J Neurosci 4:1994-2000.

White K, Hurteau T, Punsal P (1986) Neuropeptide FMR Famide-like immunoreactivity in Drosophila: development and distribution. J Comp Neurol 247:430-438.

Wiborg O, Pederson MS, Wind A, Berglund LE, Marcker KA, Vuust I (1985) The human ubiquitin multigene family: some genes contain multiply repeated ubiquitin coding sequences. EMBO J 4:755-759.

Wilde CD, Akam M (1987) Conserved sequence elements in the 5 region of the Ultrabithorax transcription unit. EMBO J 6:1393-1401.

Yang H-Y, Frata W, Majane EA, Costa E (1985) Isolation, sequencing, synthesis and pharmacological characterization of two brain neuropeptides that modulate the action of morphine. Proc Natl Acad Sci USA 82:7757-7761.

Yoshikawa K, Williams C, Sabol SL (1984) Rat brain preproenkephalin mRNA: cloning, primary structure and distribution in the central nervous system. J Biol Chem 259:14301-14308. 